Психология. Журнал Высшей школы экономики,

2018. T. 15. № 3. C. 407-426. DOI: 10.17323/1813-8918-2018-3-407-426

\title{
ОДОБРЕНИЕ ГРУППОВОЙ ИЕРАРХИИ: РУССКОЯЗЫЧНАЯ ВЕРСИЯ ШКАЛЫ ДЛЯ ИЗМЕРЕНИЯ ОРИЕНТАЦИИ НА СОЦИАЛЬНОЕ ДОМИНИРОВАНИЕ
}

\author{
О.А. ГУЛЕВИЧ ${ }^{a}$, Е.Р. АГАДУЛЛИНА ${ }^{\mathrm{a}}$, О.Е. ХУХЛАЕВ
}

\author{
`Национальный исследовательский университет «Высиая икола экономики», 101000, Россия, \\ Москва, ул. Масниикая, д. 20 \\ ${ }^{\circ}$ Московский государственньй психолого-педагогиеский университет, 127051, Россия, Москва, \\ ул. Сретенка, д. 29
}

\section{Резюме}

В статье описана русскоязычная версия опросника для измерения ориентации на социальное доминирование Ф. Пратто и Дж. Сиданиуса (Pratto et al., 1994). Рассмотрены структура, надежность и валидность трех вариантов методики: шкалы для измерения ориентации на социальное доминирование вообще (Исследование 1), в межэтнических (Исследование 2) и международных (Исследование 3) отношениях. В исследовании приняли участие 2813 респондентов $(\mathrm{N} 1=1290, \mathrm{~N} 2=204, \mathrm{~N} 3=1319)$. Они заполняли полные версии опросников, состоявшие из 16 утверждений. Респонденты должны были согласиться или не согласиться с каждым утверждением, используя 7-балльную шкалу (от 1 - «совершенно не согласен» до 7 - «совершенно согласен»). Конфирматорный анализ продемонстрировал, что модели, в которых пункты опросника образовывали два тесно связанных субфактора, лучше соответствовали данным, чем модели, в которых все пункты образовывали одну шкалу. Кроме того, выяснилось, что модели, которые включали в себя 10 утверждений, лучше соответствовали данным, чем модели, которые включали в себя 16 утверждений (Study 1: $\chi^{2}=121.737^{*}, \mathrm{CFI}=0.967, \mathrm{RMSEA}=0.050 ;$ Study $2: \chi^{2}=42.411$, CFI $=0.988$, RMSEA $=0.035$; Study 3: $\chi^{2}=134.225$, CFI $=0.967$, RMSEA $=0.047$ ). Дальнейший анализ продемонстрировал, что модели, которые включают в себя 10 пунктов, имеют хорошие показатели конфигурационной валидности. В целом полученные результаты свидетельствуют о том, что короткие версии шкал для измерения ориентации на социальное доминирование соответствуют теоретическим представлениям, обладают надежностью, валидностью и могут быть использованы в эмпирических исследованиях.

Ключевые слова: теория социального доминирования, ориентация на социальное доминирование, шкала.

Негативное отношение к социальным группам - распространенное явление в современном мире. Чаще всего его жертвой становятся сообщества, имеющие относительно низкий статус в обществе (женщины, этнические, расовые, сексуальные и религиозные меньшинства). Для объяснения отношения к этим 
сообществам психологи предложили целый ряд теорий, связанных как с индивидуальными особенностями носителей негативного отношения, так и с характеристиками групп.

К «индивидуальным» объяснениям относятся теории авторитарной личности, социального доминирования и оправдания социальной системы. Сторонники этих теорий полагают, что существуют психологические особенности, которые вызывают негативное отношение к другим группам. Для измерения этих психологических особенностей используются опросники. В этой статье речь пойдет о методике для измерения центрального понятия второй теории - ориентации на социальное доминирование.

Теория социального доминирования. Теория социального доминирования (sосіal dominance theory) была предложена американскими психологами Фелисией Пратто и Джимом Сиданиусом (Pratto et al., 2006; Sidanius et al., 2004). Согласно этой теории, человеческое общество построено по иерархическому принципу. Сообшества, находяшиеся на верхушке иерархии, обладают большими ресурсами и возможностями, чем группы, находящиеся у ее подножия.

Социальная иерархия строится вокруг трех измерений: пола, возраста и «случайных» оснований. Пол и возраст естественны, поскольку связаны с циклом жизни человека и важны для биологического выживания. «Случайные» основания, например этническая и расовая принадлежность, социально-экономический статус, политические или религиозные предпочтения, не важны с точки зрения биологического выживания, но связаны с ценностями и образом жизни людей.

При этом общества различаются как по доминирующим основаниям иерархии, так и по ее устойчивости. Например, в одних странах существует жесткая гендерная иерархия, а в других - практикуется гендерное равенство; в одних странах дети обязаны полностью подчиняться взрослым, а в других они могут действовать самостоятельно. В одних странах представители этнических меньшинств подвергаются систематической дискриминации, а в других - не подвергаются.

Согласно теории социального доминирования, социальная иерархия возникла в ходе эволюции как условие, необходимое для выживания биологического вида. В современном мире она потеряла первоначальное значение. Тем не менее, хотя некоторые основания иерархии уходят в прошлое, некоторые по-прежнему воспроизводятся. Это происходит благодаря наличию мифов и социальных институтов, которые усиливают и ослабляют иерархию.

Мифы - это распространенные в обществе системы представлений, затрагивающие социальную иерархию. Мифы, усиливающие групповую иерархию, дают интеллектуальное и моральное оправдание существующему неравенству: оправдывают превосходство одних групп над другими на основании половой, возрастной, этнической, политической, религиозной и т.д. принадлежности. В то же время мифы, ослабляющие групповую иерархию, отражают необходимость равенства.

Социальные институты - это любые организации, усиливающие или ослабляющие групповую иерархию. Институты, усиливающие иерархию, 
например большой бизнес или правоохранительные органы, закрепляют существующую в обществе систему власти. В то же время институты, ослабляющие иерархию, например благотворительные организации или общественные движения, защищающие права человека, открывают дополнительные возможности для членов низкостатусных групп.

Содержание ориентации на социальное доминирование. Под воздействием мифов и социальных институтов у людей формируется ориентация на социальное доминирование (social dominance orientation) - отношение человека к существующей в обществе социальной иерархии, доминированию одних групп над другими. Люди с сильно выраженной ориентацией на социальное доминирование поддерживают существуюшую групповую иерархию и выступают против группового равенства, тогда как люди со слабо выраженной ориентацией поддерживают идею равенства и выступают против групповой иерархии.

Для измерения ориентации на социальное доминирование Дж. Сиданиус и Ф. Пратто создали опросник (Pratto et al., 1994). Вопросы оригинального варианта методики были сформулированы на английском языке. Позже они были переведены на другие языки и стали использоваться во многих странах. Опросник состоит из 16 утверждений, которые образуют две субшкалы доминирования и антиэгалитаризма. Некоторые исследования показывают, что субшкала доминирования лучше предсказывает явные, а субшкала антиэгалитаризма - скрытые формы предрассудков (Ho et al., 2012). Эти субшкалы, в свою очередь, образуют общую шкалу ориентации на социальное доминирование.

Оригинальный вариант методики измеряет отношение человека к социальному неравенству вообще, вне зависимости от измерения, по которому оно возникает (расовое, этническое, гендерное, возрастное, социально-экономическое и т.д.). При его заполнении респонденты соглашаются или не соглашаются с утверждениями, касающимися отношений равенства или доминирования между любыми группами, существующими в обществе. Таким образом, в основе этой методики лежит дискурс, связанный с необходимостью социального равенства как такового.

Однако при использовании этой методики могут возникнуть две сложности. Во-первых, выражая свое отношение к равенству или доминированию одних групп над другими, люди могут думать об определенных видах иерархии (например, гендерной или этнической/расовой). Это более характерно для тех стран, в которых идея группового равенства как такового обсуждается редко, но внимание привлекают отдельные виды иерархии. На наш взгляд, к числу таких стран относится Россия.

Идея социального равенства занимает важное место в российском дискурсе. Однако разговоры о равенстве большей частью касаются равенства в экономической сфере (уровень доходов, возможности для развития) и апеллируют к экономическому основанию социальной иерархии (богатые vs бедные). Другие виды иерархии - гендерная, этническая, политическая, религиозная - вызывают гораздо меньший интерес. Чтобы измерить отношение 
людей к иерархии в этих сферах, нужно «погрузить» их в соответствуюший контекст.

Во-вторых, изначально ориентация на социальное доминирование рассматривалась как индивидуальная особенность, определяющая отношение человека к группам меньшинства и большинства, сосуществующим в рамках одного государства (например, мужчинам и женшинам, членам разных этнических и расовых групп). Поэтому методика измеряет отношение человека к иерархии между группами, проживающими на территории одной страны. Чтобы измерять отношение к международной иерархии, она нуждается в некоторых измерениях.

Специфика ориентации на социальное доминирование. Психологические исследования показывают, что ориентация на социальное доминирование связана с правым авторитаризмом (некритическим одобрением существующих в стране политических лидеров и распространенных социальных норм) и оправданием системы (безоговорочным одобрением политической и экономической системы страны). Вопрос о связи между этими характеристиками привлек внимание исследователей в конце 1990-х - начале 2000-х гг. В этот период в научной литературе развернулась дискуссия о том, насколько эти показатели связаны друг с другом.

Это, прежде всего, касалось авторитаризма и ориентации на социальное доминирование. Одни психологи утверждали, что правый авторитаризм и ориентация на социальное доминирование - это две формулировки одного и того же отношения к социальной системе. Они обращали внимание на позитивную связь между этими переменными, которая была обнаружена во многих американских и европейских исследованиях. Другие исследователи проводили четкое различие между ними. По их мнению, правый авторитаризм касается отношения человека к верхушке «пирамиды» - к людям, занимающим ключевые политические позиции, и распространенным социальным нормам, тогда как ориентация на социальное доминирование - к групповой иерархии в обществе.

Более поздние исследования продемонстрировали, что ориентация на социальное доминирование действительно отличается от правого авторитаризма. Во-первых, эти проявления свойственны людям с разными чертами и ценностями. Высокий уровень правого авторитаризма демонстрируют люди с низкой открытостью новому опыту, высоким уровнем когнитивной завершенности и сильно выраженными ценностями консерватизма. В то же время высокий уровень ориентации на социальное доминирование свойствен людям с низким уровнем доброжелательности и сильно выраженными ценностями самовозвышения (Feather, McKee, 2012; Hodson, Dhont, 2015; Livi et al., 2014).

Во-вторых, ориентация на социальное доминирование и правый авторитаризм по-разному сопряжены с отношением к социальным группам. В целом психологические исследования показали, что обе переменные связаны между собой и предсказывают наличие предрассудков в отношении к расовым и этническим меньшинствам, мигрантам, женщинам, гомосексуалам и религиозным аутгруппам (Hodson, Dhont, 2015). Однако они вносят независимый 
вклад в негативное отношение к этим сообществам. Эта идея отражена в модели Дж. Даккита (Duckitt, 2001), которая получила значительную эмпирическую поддержку (Perry et al., 2013; Sibley, Duckitt, 2008; Sibley et al., 2006).

Связь между ориентацией на социальное доминирование и оправданием социальной системы привлекла меньший интерес исследователей. Содержательное различие между ними заключается в том, что ориентация на социальное доминирование отражает отношение к групповой иерархии в обществе, а оправдание социальной системы - к существующей экономической и политической структуре общества, какой бы она ни была. В целом психологические исследования, проведенные в североамериканских и европейских странах, показывают, что ориентация на социальное доминирование позитивно связана с оправданием социальной системы (Everett, 2013; Jylhä, Akrami, 2015; Mosso et al., 2013), однако то и другое по-разному сопряжено с отношением к социальным группам (Mosso et al., 2013).

Таким образом, ориентация на социальное доминирование является отдельной характеристикой, которая самостоятельно предсказывает отношение к различным социальным группам. Цель данного исследования - определение надежности и структурной валидности русскоязычной версии опросника Дж. Сиданиуса и Ф. Пратто. Наше исследование включало в себя три этапа. На первом этапе был использован классический вариант опросника, измеряющий отношение людей к социальной иерархии внутри общества. На втором и третьем этапах были использованы модифицированные варианты опросника для измерения ориентации на социальное доминирование в этнических и международных отношениях.

\section{Исследование 1}

\section{Memod}

Выборка. В исследовании приняли участие две группы респондентов. Первая группа включала в себя 512 жителей России, 86.5\% женщин, 13.5\% мужчин в возрасте от 18 до 69 лет $(\mathrm{M}=20.36, \mathrm{SD}=6.47)^{1}$. Во вторую группу вошли 778 жителей России, 71\% женщин, 29\% мужчин в возрасте от 18 до 79 лет $(\mathrm{M}=23.38, \mathrm{SD}=7.58)^{2}$.

Опросник для измерения общей ориентации на соииальное доминирование. Русскоязычная версия опросника была создана на базе оригинальной методики, разработанной Дж. Сиданиусом и Ф. Пратто. Все пункты были переведены на русский язык. Получившиеся формулировки обсуждались в двух малых группах (5 и 6 человек). Участники описывали, как они понимают смысл каждого суждения, и оценивали его понятность. В результате некоторые формулировки были изменены.

\footnotetext{
${ }^{1}$ Данные были собраны в ходе исследования, которое проводил В. Кривощеков.

2 Данные были собраны в ходе исследования, которое проводила М. Балезина.
} 
Итоговая версия опросника представлена в приложении 1. Она включает в себя 8 прямых и 8 обратных утверждений. Прямые пункты образуют субшкалу «Доминирование», а обратные пункты - субшкалу «Антиэгалитаризм». При обработке результатов обратные пункты переворачиваются. Человек может согласиться или не согласиться с каждым утверждением, отметив свой ответ на 7-балльной шкале (от 1 - «совершенно не согласен» до 7 - «совершенно согласен»).

\section{Результать}

Структура опросника. Для проверки структуры русскоязычной версии опросника использовался метод конфирматорного факторного анализа. В ходе исследования проверялись однофакторная и двухфакторная модели. В однофакторной модели все пункты опросника образуют один фактор; в двухфакторной модели они образуют субфакторы доминирования и антиэгалитаризма, которые тесно связаны между собой.

Результаты, полученные при анализе полной версии опросника, представлены в таблице 1. Они свидетельствуют о том, что однофакторная модель плохо соответствует эмпирическим данным. Двухфакторная модель имеет лучшие, но недостаточно хорошие показатели соответствия.

Анализ индексов модификации показал, что среди суждений методики наблюдаются значимые устойчивые ковариации ошибок. Например, наблюдается сильная связь при ответе на суждения 9 и $14\left(\chi^{2}=128.892\right), 2$ и $4\left(\chi^{2}=45.489\right)$, 3 и $7\left(\chi^{2}=32.916\right)$. Анализ этих пунктов показывает, что связанные между собой суждения похожи по смыслу, а в некоторых случаях даже по использованию слов.

Ковариации между этими пунктами были добавлены в модель. Результаты повторного анализа с добавлением трех ковариирующих пар суждений свидетельствуют о том, что двухфакторная модель демонстрирует удовлетворительное соответствие всем требуемым показателям, в то время как однофакторная модель по-прежнему плохо соответствует эмпирическим данным.

Чтобы в дальнейшем не перегружать респондентов пунктами со схожим смыслом и формулировками, было принято решение проанализировать короткий вариант методики. Для формирования короткой версии из каждой пары ковариирующих суждений были удалены суждения с наименьшей стандартизованной факторной нагрузкой. Итоговый вариант короткой версии опросника состоял из 10 суждений, по 5 суждений в каждой субшкале (см. приложение 1).

Из таблицы 1 видно, что показатели однофакторной модели короткой версии опросника лучше, чем показатели полной версии, но тем не менее не соответствуют установленным показателям. В то же время двухфакторная модель демонстрирует хорошее соответствие эмпирическим данным, без учета дополнительных связей (см. рисунок 1), поэтому дальнейший анализ был проведен для двухфакторной модели короткой версии опросника.

Показатели надежности, средние значения и стандартные отклонения короткой версии методики представлены в таблице 2. Они свидетельствуют о 


\begin{tabular}{|l|c|c|c|c|c|c|c|c|c|c|}
\hline \multicolumn{1}{|c|}{ Модели } & $\boldsymbol{x}^{2}$ & df & CFI & TLI & RMSEA & SRMR & AIC & BIC \\
\hline \multicolumn{7}{|c|}{ Однофакторная модель } \\
\hline Полная версия & $1217.943^{*}$ & 104 & 0.788 & 0.755 & 0.101 & 0.080 & 59675.840 & 59913.663 \\
\hline $\begin{array}{l}\text { Полная версия с учетом трех } \\
\text { ковариаций }\end{array}$ & $850.767^{*}$ & 101 & 0.857 & 0.830 & 0.084 & 0.071 & 59152.190 & 59404.877 \\
\hline Короткая версия & $240.954^{*}$ & 34 & 0.921 & 0.896 & 0.076 & 0.054 & 37272.479 & 37426.073 \\
\hline & & Двухфакторная модель & & \\
\hline Полная версия & $554.865^{*}$ & 103 & 0.914 & 0.900 & 0.065 & 0.050 & 58727.827 & 58970.604 \\
\hline $\begin{array}{l}\text { Полная версия с учетом трех } \\
\text { ковариаций }\end{array}$ & $349.259^{*}$ & 100 & 0.952 & 0.943 & 0.049 & 0.041 & 58441.881 & 58699.523 \\
\hline Короткая версия & $121.737^{*}$ & 34 & 0.967 & 0.956 & 0.050 & 0.034 & 37109.679 & 37263.273 \\
\hline
\end{tabular}

Примечание. Здесь и далее: $\chi^{2}$ - критерий хи-квадрат; $\mathrm{df}$ - число степеней свободы; CFI - показатель сравнительного соответствия; TLI ненормированный показатель соответствия; RMSEA - среднеквадратическая ошибка оценки; SRMR - стандартизированный корень среднеквадратического остатка; АIC - информационный критерий Акайке.

$$
\text { * }-p<0.001 \text {. }
$$


том, что субшкалы «Доминирование» и «Антиэгалитаризм», так же как и общая шкала ориентации на социальное доминирование, имеют хорошие показатели надежности.

Структурная валидность опросника. Для проверки структурной валидности короткой версии методики был проведен мультигрупповой факторный анализ. Респонденты были разделены по половой принадлежности. Было проанализировано три вида инвариантности: конфигурационная (свидетельствующая о том, что в разных группах суждения складываются в идентичные шкалы); метрическая (указывающая на то, что в разных группах нагрузки суждений в факторах идентичны); и скалярная (указывающая на то, что нагрузки разных суждений вносят эквивалентный вклад в латентную переменную).

Рисунок 1

Структура опросника для измерения общей ориентации на социальное доминирование

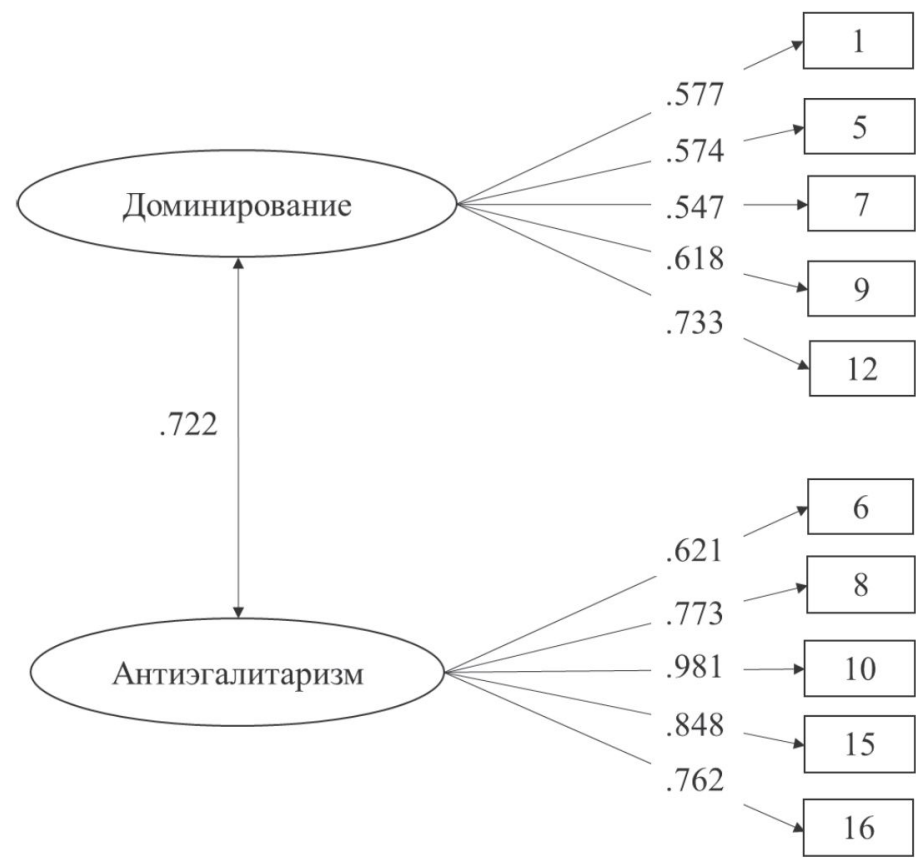

Таблица 2

Описательная статистика для короткой версии опросника

\begin{tabular}{|c|c|c|c|}
\hline Шкала & $\boldsymbol{\alpha}$ & $\mathbf{M}$ & SD \\
\hline Доминирование & 0.76 & 3.56 & 1.22 \\
\hline Антиэгалитаризм & 0.85 & 3.19 & 1.18 \\
\hline Общий показатель & 0.85 & 3.38 & 1.04 \\
\hline
\end{tabular}


Результаты мультигруппового анализа показали, что короткая версия методики демонстрирует конфигурационную инвариантность $\left(\chi^{2}(68)=172.289\right.$, $p<0.001$, RMSEA [90\% CI] $=0.049[0.040 ; 0.058]$, SRMR $=0.038$, CFI $=0.968$, $\mathrm{TLI}=0.958, \mathrm{AIC}=46167)$. Однако не удается провести проверку метрической и скалярной инвариантности. Этот результат показывает, что структура методики воспроизводится на разных подвыборках, однако не позволяет сделать других выводов.

\section{Исследование 2}

\section{Memod}

Выборка. В исследовании приняли участие 99 студентов театрального художественно-технического колледжа и 105 студентов Московского государственного психолого-педагогического университета, среди них 53.4\% мужчин и 46.6\% женщин в возрасте от 16 до 29 лет $(\mathrm{M}=18.6, \mathrm{SD}=2.1)^{3}$. Все участники заполняли бумажную форму опросника.

Опросник для измерения ориентации на социальное доминирование в межәтнических отношениях. Русскоязычная версия опросника была создана на базе оригинальной методики для измерения ориентации на социальное доминирование, описанной в предыдущем исследовании. Пункты опросника были переформулированы таким образом, чтобы они отражали специфику отношений между народами. В инструкции к опроснику был сделан акцент на отношениях между народами, проживающими в одной стране.

Затем было проведено когнитивное интервью с участием 12 человек. В ходе интервью участники отвечали на вопросы о каждом пункте опросника. Интервьюер выяснял, как респондент понимает смысл вопросов методики, есть ли трудности с пониманием. По результатам когнитивного интервью ряд формулировок был уточнен. Итоговая версия опросника представлена в приложении 2.

\section{Результать}

Анализ результатов проводился так же, как в первом исследовании. В ходе анализа были проанализированы полная и короткая версии опросника. Короткая версия методики была создана на основе полной версии путем удаления ковариирующих суждений с меньшей стандартизованной факторной нагрузкой.

Структура опросника. Результаты конфирматорного факторного анализа для полной и короткой версий опросника представлены в таблице 3. Они свидетельствуют о том, что однофакторная модель полной и короткой версий опросника плохо соответствует данным. Двухфакторная модель полной версии опросника также имеет неудовлетворительные показатели. В то же время

\footnotetext{
${ }^{3}$ Данные были собраны в ходе исследования, которое проводила А. Фролова.
} 
Показатели опросника для измерения ориентации на социальное доминирование в межэтнических отношениях

\begin{tabular}{|l|c|c|c|c|c|c|c|c|c|}
\hline \multicolumn{1}{|c|}{ Модели } & $\boldsymbol{\chi}^{2}$ & df & CFI & TLI & RMSEA & SRMR & AIC & BIC \\
\hline \multicolumn{1}{|c|}{ Однофакторная модель } \\
\hline Полная версия & $484.064^{*}$ & 104 & 0.714 & 0.670 & 0.134 & 0.115 & 12301.125 & 12460.395 \\
\hline Короткая версия & $132.706^{*}$ & 35 & 0.858 & 0.818 & 0.117 & 0.087 & 7526.820 & 7626.363 \\
\hline \multicolumn{1}{|c|}{ Двухфакторная модель } \\
\hline Полная версия & $253.989^{*}$ & 103 & 0.886 & 0.867 & 0.085 & 0.087 & 12036.227 & 12198.814 \\
\hline Короткая версия & 42.411 & 34 & 0.988 & 0.984 & 0.035 & 0.041 & 7411.262 & 7514.124 \\
\hline
\end{tabular}

Таблица 4

Показатели опросника для измерения ориентации на социальное доминирование в международных отношениях

\begin{tabular}{|l|c|c|c|c|c|c|c|c|c|}
\hline \multicolumn{1}{|c|}{ Модели } & $\chi^{2}$ & df & CFI & TLI & RMSEA & SRMR & AIC & ВIC \\
\hline \multicolumn{7}{|c|}{ Однофакторная модель } \\
\hline Полная версия & $1186.501^{*}$ & 104 & 0.801 & 0.771 & 0.089 & 0.086 & 71793.858 & 72042.720 \\
\hline Короткая версия & $327.365^{*}$ & 35 & 0.904 & 0.877 & 0.080 & 0.066 & 43306.942 & 43462.481 \\
\hline \multicolumn{7}{|c|}{ Двухфакторная модель } \\
\hline Полная версия & $761.667^{*}$ & 103 & 0.879 & 0.859 & 0.070 & 0.069 & 71161.110 & 71415.157 \\
\hline Короткая версия & $134.225^{*}$ & 34 & 0.967 & 0.956 & 0.047 & 0.040 & 42992.868 & 43153.591 \\
\hline
\end{tabular}


двухфакторная модель короткой версии опросника соответствует всем требуемым показателям (см. рисунок 2), поэтому в дальнейшем анализировалась короткая версия методики.

Показатели надежности, средние значения и стандартные отклонения короткой версии методики представлены в таблице 4. Они свидетельствуют о том, что субшкалы «Доминирование» и «Антиэгалитаризм», так же как и общая шкала ориентации на социальное доминирование, имеют хорошие показатели надежности.

Структурная валидность опросника. Для проверки структурной валидности опросника был проведен мультигрупповой факторный анализ.

Рисунок 2

Структура опросника для измерения ориентации на социальное доминирование в межэтнических отношениях

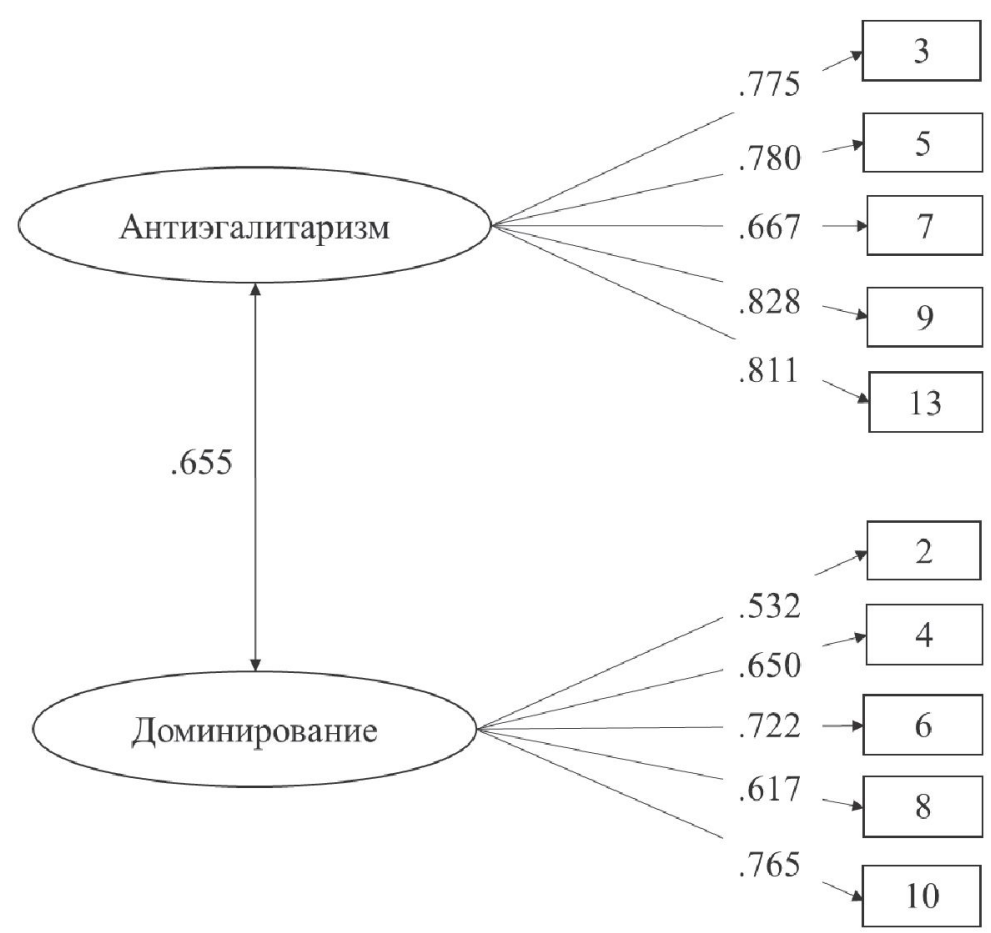

Описательная статистика для короткой версии опросника

\begin{tabular}{|c|c|c|c|}
\hline Шкала & $\alpha$ & $\mathbf{M}$ & $\mathbf{S D}$ \\
\hline Доминирование & 0.79 & 3.44 & 1.44 \\
\hline Антиэгалитаризм & 0.88 & 2.55 & 1.39 \\
\hline Общий показатель & 0.87 & 3.00 & 1.24 \\
\hline
\end{tabular}


Респонденты были разделены по половой принадлежности. Результаты анализа показывают, что короткая версия методики демонстрирует конфигурационную инвариантность $\left(\chi^{2}(68)=94.245, p<0.05\right.$, RMSEA [90\% CI] $=0.062$ $[0.026 ; 0.090], \mathrm{SRMR}=0.054, \mathrm{CFI}=0.952, \mathrm{TLI}=0.936, \mathrm{AIC}=7429$ ). Однако не удается провести проверку метрической и скалярной инвариантности. Это соответствует полученному в предыдущем исследовании с использованием классической методики для измерения общей ориентации на социальное доминирование.

\section{Исследование 3}

\section{Memod}

Выборка. В исследовании приняли участие две группы респондентов. Первую группу составили 897 жителей России, среди них 51.5\% мужчин и $48.5 \%$ женщин в возрасте от 18 до 80 лет $(\mathrm{M}=46.2, \mathrm{SD}=12.3)^{4}$. Вторую группу составили 422 человека, среди них 175 мужчин и 247 женщин в возрасте от 18 до 30 лет $(\mathrm{M}=20.94, \mathrm{SD}=2.26)^{5}$. Все участники заполняли электронную форму опросника.

Опросник для измерения ориентации на социальное доминирование в международных отношениях. Методика, которая использовалась в этом исследовании, была аналогична опроснику, который использовался в предыдущем исследовании. Единственное отличие состояло в том, что в инструкции к опроснику был сделан акцент на отношениях между народами, проживающими в разных странах.

\section{Результать}

Анализ результатов проводился так же, как в первом исследовании. В ходе анализа были проанализированы полная и короткая версии опросника (см. Исследование 2).

Структура опросника. Результаты конфирматорного факторного анализа для полной и короткой версии опросника представлены в таблице 5. Они свидетельствуют о том, что однофакторная модель полной и короткой версий опросника плохо соответствует данным. Двухфакторная модель полной версии опросника также имеет неудовлетворительные показатели. В то же время двухфакторная модель короткой версии опросника соответствует всем требуемым показателям (см. рисунок 3), поэтому в дальнейшем анализировалась короткая версия методики.

Показатели надежности, средние значения и стандартные отклонения короткой версии методики представлены в таблице 6 . Они свидетельствуют о том, что субшкалы «Доминирование» и «Антиэгалитаризм», так же как и

\footnotetext{
${ }^{4}$ Данные были собраны в ходе исследования, которое проводил А. Неврюев.

${ }^{5}$ Данные были собраны в ходе исследования, которое проводила И. Прусова.
} 
Рисунок 3

Структура опросника для измерения ориентации на социальное доминирование в международных отношениях

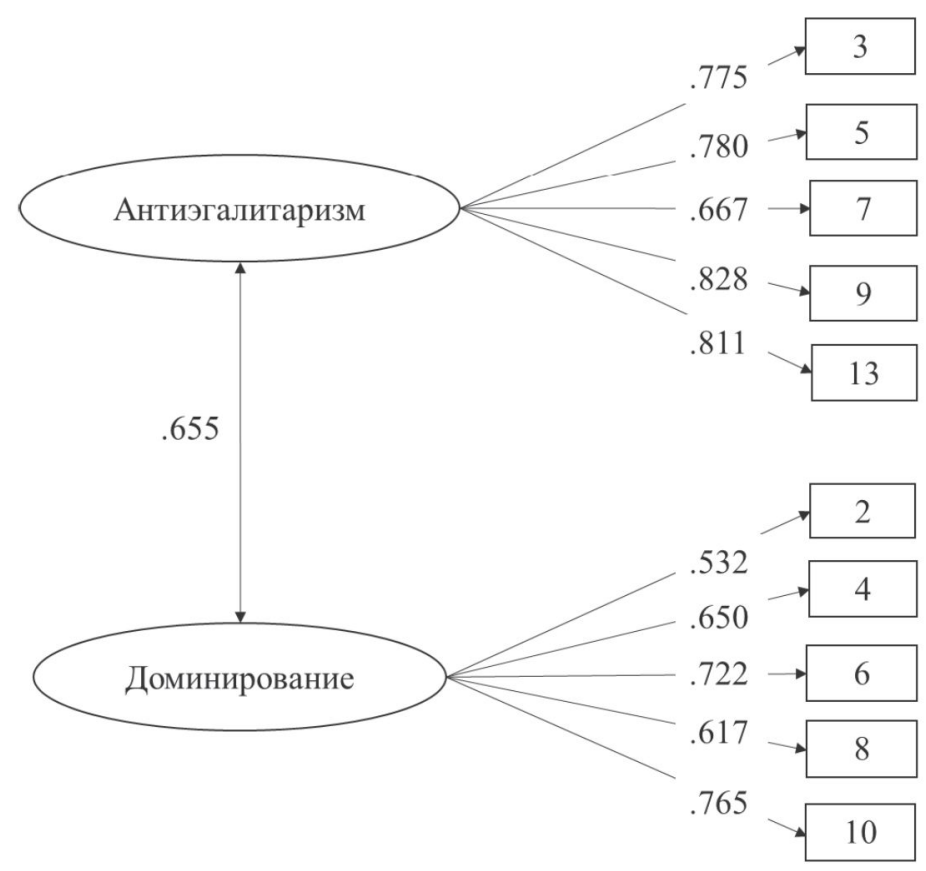

Таблица 6

Описательная статистика для короткой версии опросника

\begin{tabular}{|c|c|c|c|}
\hline Шкала & $\boldsymbol{\alpha}$ & $\mathbf{M}$ & SD \\
\hline Доминирование & 0.71 & 3.15 & 1.14 \\
\hline Антиэгалитаризм & 0.88 & 2.42 & 1.06 \\
\hline Общий показатель & 0.84 & 2.78 & 0.97 \\
\hline
\end{tabular}

общая шкала ориентации на социальное доминирование, имеют хорошие показатели надежности.

Структурная валидность опросника. Для проверки структурной валидности короткой версии методики был проведен мультигрупповой факторный анализ. Респонденты были разделены по половой принадлежности. Результаты анализа показывают, что короткая версия методики демонстрирует конфигурационную инвариантность $\left(\chi^{2}(68)=153.168, p<0.001\right.$, RMSEA $[90 \% \mathrm{CI}]=0.044[0.034 ; 0.053], \mathrm{SRMR}=0.043, \mathrm{CFI}=0.964, \mathrm{TLI}=0.953, \mathrm{AIC}=$ = 42978). Провести проверку метрической и скалярной инвариантности не удается. Это соответствует результатам предыдущего исследования, в котором использовалась та же методика с другой инструкцией. 


\section{Обсуждение}

Ориентация на социальное доминирование - одна из ключевых индивидуальных особенностей, которые предсказывают отношение людей к членам социальных групп. Для измерения этой ориентации исследователи используют опросник, предложенный американскими психологами. На протяжении последних двадцати лет эта методика обрела широкую популярность, была переведена на разные языки, например японский (Mifune, Yamagishi, 2008), испанский (Etchezahar et al., 2014) и китайский (Li et al., 2006). Однако стоит учитывать, что, создавая методику, авторы отталкивались от определенного социального дискурса со своей стилистикой. Поскольку такой дискурс культурно-специфичен, возникает необходимость адаптации этой методики для использования в других странах. В данном исследовании мы проанализировали структуру этого опросника на русскоязычной выборке. Этот анализ позволил нам сделать несколько выводов.

Во-первых, опросник для измерения ориентации на социальное доминирование имеет двухфакторную структуру. Один компонент включает в себя утверждения, связанные с желательностью/необходимостью доминирования одних групп над другими, а другой компонент - с желательностью/необходимостью равенства между группами. Эти компоненты тесно связаны между собой, но тем не менее не образуют единого фактора. Эта структура соответствует представлениям авторов методики, однако не соответствует распространенной исследовательской практике, при которой вычисляется единый показатель ориентации на социальное доминирование. Это означает, что выбор между одним общим или двумя отдельными показателями при проведении исследования определяется теоретическими представлениями и остается за исследователем.

Во-вторых, короткая версия опросника лучше соответствует полученным данным, чем длинная. Это происходит, поскольку длинная версия опросника содержит суждения с одинаковым смыслом и повторяющимися формулировками, ответы на которые сильно ковариируют друг с другом. Сокращение методики за счет удаления таких пунктов улучшает ее показатели и избавляет респондентов от необходимости по несколько раз реагировать на одни и те же суждения. Стоит отметить, что необходимость создания короткой версии осознается исследователями из разных стран. В частности, при участии авторов методики в 2015 г. был предложен короткий вариант методики для оценки ориентации на социальное доминирование (Ho et al., 2015). Адаптации методики в других странах также используют различные сокращенные варианты, в которые входят от 8 до 10 суждений (см., например: Etchezahar et al., 2014).

В-третьих, опросник может использоваться для измерения как общей ориентации на социальное доминирование относительно любых социальных групп, так и частной ориентации, касающейся отдельных измерений иерархии. Классический опросник позволяет измерить общее одобрение или неодобрение человеком группового равенства/иерархии внутри общества. Он лучше соответствует идеям теории социального доминирования и используется 
в подавляющем большинстве исследований. Однако он не позволяет выявить, о каких группах думает респондент. В то же время опросники для измерения отношения к равенству/иерархии в межэтнических и международных отношениях «погружают» респондента в определенный контекст, но не позволяют измерить общее отношение к идее группового равенства, поэтому выбор общего или частного варианта методики зависит от теоретических соображений автора исследования.

В целом описанные в статье результаты указывают на то, что короткая версия методики для измерения ориентации на социальное доминирование может быть использована в будущих исследованиях как надежный инструментарий. Она позволит получать данные, которые будут сопоставимы с результатами, полученными исследователями из других стран.

Ссылки на зарубежные источники см. в разделе References после англоязыного блока.

\section{Общая ориентация на социальное доминирование}

Приложение 1

В современном обществе существует множество различных групп. Мы предлагаем вам подумать о том, как должны быть построены отношения между разными группами людей. Отметьте, в какой степени вы согласны с приведенными ниже утверждениями, используя следующую шкалу:

\begin{tabular}{|c|c|c|c|c|c|c|}
\hline 1 & 2 & 3 & 4 & 5 & 6 & 7 \\
\hline $\begin{array}{c}\text { Совершенно } \\
\text { не согласен }\end{array}$ & $\begin{array}{c}\text { Не } \\
\text { согласен }\end{array}$ & $\begin{array}{c}\text { Скорее не } \\
\text { согласен }\end{array}$ & $\begin{array}{c}\text { Не } \\
\text { уверен }\end{array}$ & $\begin{array}{c}\text { Скорее } \\
\text { согласен }\end{array}$ & Согласен & $\begin{array}{c}\text { Совершенно } \\
\text { согласен }\end{array}$ \\
\hline
\end{tabular}

\section{Полная версия}

1. Одни группы людей лучше, чем другие.

2. Мы должны стремиться к тому, чтобы члены разных групп имели равные доходы.

3. Чтобы получить то, что хочешь, иногда необходимо применить силу против других групп людей.

4. Равенство между разными группами - это то, к чему следует стремиться.

5. Одни группы людей должны иметь больше возможностей в жизни, чем другие.

6. Одни группы не должны доминировать над другими.

7. Чтобы преуспеть в жизни, иногда необходимо игнорировать интересы других групп.

8. Хорошо, когда существует равенство между разными группами людей.

9. Если бы некоторые группы людей «знали свое место», в обществе было бы меньше проблем.

10. Если мы будем относиться к разным группам людей как к равным, в нашем обществе станет меньше проблем. 
11. Одни группы заслуживают того, чтобы быть «на вершине», а другие группы «внизу».

12. Группы с низким статусом должны «знать свое место».

13. Всем группам должны быть предоставлены равные возможности в жизни.

14. Некоторые группы людей временами нужно «ставить на место».

15. Равенство между группами идет на благо обществу.

16. Мы должны делать все, что в наших силах, чтобы разные группы имели равные условия жизни.

\section{К̈люч:}

Субикала «Антиәгалитаризм»: 2, 4, 6, 8, 10, 13, 15, 16 (обратные пункты, при обработке переворачиваются)

Субикала «Доминирование»: 1, 3, 5, 7, 9, 11, 12, 14 (прямые пункты)

\section{Короткая версия}

1. Одни группы людей лучше, чем другие.

2. Одни группы людей должны иметь больше возможностей в жизни, чем другие.

3. Одни группы не должны доминировать над другими.

4. Чтобы преуспеть в жизни, иногда необходимо игнорировать интересы других групाп.

5. Хорошо, когда существует равенство между разными группами людей.

6. Если бы некоторые группы людей «знали свое место», в обществе было бы меньше проблем.

7. Если мы будем относиться к разным группам людей как к равным, в нашем обществе станет меньше проблем.

8. Группы с низким статусом должны «знать свое место».

9. Равенство между группами идет на благо обществу.

10. Мы должны делать все, что в наших силах, чтобы разные группы имели равные условия жизни.

\section{Ключ:}

Субикала «Антиәгалитаризл»: 3, 5, 7, 9, 10 (обратные пункты, при обработке переворачиваются)

Субикала «Доминирование»: 1, 2, 4, 6, 8 (прямые пункты) 
Ориентация на социальное доминирование в межэтнических/международных отношениях

Инструкция для иерархии между этническими группами внутри одной страны: Сегодня в мире практически не существует стран, на территории которых живут представители только одного народа (этноса). Болышинство современных государств являются многонациональными. Мы предлагаем подумать - как должны быть построены отношения между разными народами, проживающими на территории одной страны. Отметьте, в какой степени вы согласны с приведенными ниже утверждениями.

\begin{tabular}{|c|c|c|c|c|c|c|}
\hline 1 & 2 & 3 & 4 & 5 & 6 & 7 \\
\hline $\begin{array}{c}\text { Совершенно } \\
\text { не согласен }\end{array}$ & $\begin{array}{c}\text { Не } \\
\text { согласен }\end{array}$ & $\begin{array}{c}\text { Скорее не } \\
\text { согласен }\end{array}$ & $\begin{array}{c}\text { Не } \\
\text { уверен }\end{array}$ & $\begin{array}{c}\text { Скорее } \\
\text { согласен }\end{array}$ & Согласен & $\begin{array}{c}\text { Совершенно } \\
\text { согласен }\end{array}$ \\
\hline
\end{tabular}

Инструкция для иерархии между разными странами: Сегодня в мире существует более 250 стран. Мы предлагаем подумать, как должны быть построены отношения между народами, проживающими в разных странах. Отметьте, в какой степени вы согласны с приведенными ниже утверждениями.

\begin{tabular}{|c|c|c|c|c|c|c|}
\hline 1 & 2 & 3 & 4 & 5 & 6 & 7 \\
\hline $\begin{array}{c}\text { Совершенно } \\
\text { не согласен }\end{array}$ & $\begin{array}{c}\text { Не } \\
\text { согласен }\end{array}$ & $\begin{array}{c}\text { Скорее не } \\
\text { согласен }\end{array}$ & $\begin{array}{c}\text { Не } \\
\text { уверен }\end{array}$ & $\begin{array}{c}\text { Скорее } \\
\text { согласен }\end{array}$ & Согласен & $\begin{array}{c}\text { Совершенно } \\
\text { согласен }\end{array}$ \\
\hline
\end{tabular}

Ответы не подразделяются на «правильные» и «неправильные». Самый лучший ответ - это ваше личное мнение. Можете быть уверены, что, каково бы ни было ваше мнение, найдется много людей, которые с вами согласятся или будут придерживаться иной точки зрения.

\section{Полная версия}

1. Хорошо, когда существует равенство между народами.

2. Каждый народ должен «знать свое место» в человеческом обществе.

3. Все народы должны обладать равными возможностями.

4. Чтобы защитить интересы одного народа, иногда нужно применить силу против других народов.

5. Мы должны стремиться к тому, чтобы разные народы имели равные условия (для жизни, развития).

6. Нормально, когда одни народы имеют больше возможностей, чем другие.

7. Равенство между народами идет на благо обществу.

8. Чтобы один народ преуспел в жизни, иногда необходимо делать то, что не нравится другим народам.

9. Нужно стремиться к тому, чтобы уровень жизни разных народов выравнивался.

10. Хорошо, когда одни народы обладают бо́льшими правами, чем другие.

11. Нехорошо, когда один народ занимает более высокое положение в человеческом обществе, чем другие.

12. Есть такие народы, которые во многом превосходят другие народы. 
13. Нашим идеалом должно быть равенство между народами.

14. Если бы некоторые народы «знали свое место», в человеческом обществе было бы меньше проблем.

15. Если будет равенство между народами, в человеческом обществе станет меньше проблем.

16. Некоторые народы временами нужно «ставить на место».

\section{Ключ:}

Субикала «Антиэгалитаризм»: 1, 3, 5, 7, 9, 11, 13, 15 (обратные пункты)

Субикала «Доминирование»: 2, 4, 6, 8, 10, 112, 14, 16 (прямые пункты)

\section{Короткая версия}

1. Каждый народ должен «знать свое место» в человеческом обществе.

2. Все народы должны обладать равными возможностями.

3. Чтобы защитить интересы одного народа, иногда нужно применить силу против других народов.

4. Мы должны стремиться к тому, чтобы разные народы имели равные условия (для жизни, развития).

5. Нормально, когда одни народы имеют больше возможностей, чем другие.

6. Равенство между народами идет на благо обществу.

7. Чтобы один народ преуспел в жизни, иногда необходимо делать то, что не нравится другим народам.

8. Нужно стремиться к тому, чтобы уровень жизни разных народов выравнивался. 9. Хорошо, когда одни народы обладают бо́льшими правами, чем другие.

10. Нашим идеалом должно быть равенство между народами.

\section{Ключ:}

Субикала «Антиэгалитаризм»: 2, 4, 6, 8, 10 (обратные пункты)

Субикала «Доминирование»: 1, 3, 5, 7, 9 (прямые пункты)

Гулевич Ольга Александровна - профессор, департамент психологии, факультет социальных наук, Национальный исследовательский университет «Высшая школа экономики», доктор психологических наук.

Сфера научных интересов: психология межгрупповых отношений, политическая психология. Контакты: ogulevich@hse.ru

Агадуллина Елена Рафиковна - доцент, департамент психологии, факультет социальных наук, Национальный исследовательский университет «Высшая школа экономики», кандидат психологических наук.

Сфера научных интересов: психология социального познания, обыденные теории.

Контакты: eagadullina@hse.ru

Хухлаев Олег Евгеньевич - доцент, кафедра этнопсихологии и психологических проблем поликультурного образования, Московский государственный психолого-педагогический университет, кандидат психологических наук.

Сфера научных интересов: кросс-культурная психология, психология межгрупповых отношений, социально-психологический тренинг.

Контакты: huhlaevoe@mgppu.ru 


\title{
Approval of Group Hierarchy: Russian Version of Social Dominance Orientation Scale
}

\author{
O.A. Gulevich ${ }^{a}$, E.R. Agadullina ${ }^{a}$, O.E. Khukhlaev ${ }^{b}$ \\ ${ }^{a}$ National Research University Higher. School of Economics, 20 Myasnitskaya Str., Moscow, 101000, \\ Russian Federation \\ ${ }^{6}$ Moscow State University of Psychology and Education, 29 Sretenka Str., Moscow, 127051, Russian \\ Federation
}

\begin{abstract}
The article describes the Russian version of Social Dominance Orientation Scale. The structure, reliability and validity of three variants of the scale were studied: scale for measurement of general social dominance (Study 1), of dominance in interethnic (Study 2) and international (Study 3) relationships. Two thousand thirty five respondents took part in the studies (N1 = 512, N2 = 204, N3 = 1319). They filled in full versions of the scales, which comprised 16 items. Respondents were to agree or disagree with each statement on a 7-score scale (from 1 - "completely disagree" to 7 - "completely agree"). Confirmatory factor analysis demonstrated that the model, where items formed 2 closely interrelated sub-factors, better fitted the data, than models, where all items were summed in one scale. Moreover, it was found that models, which comprised 10 items, better fitted the data, than models with 16 items (Study 1: $\chi^{2}=121.737^{*}$, CFI $=0.967$, RMSEA $=0.050 ;$ Study $2: \chi^{2}=42.411$, $\mathrm{CFI}=0.988$, RMSEA $=0.035$; Study $3: \chi^{2}=134.225$, CFI $=0.967$, RMSEA $=0.047$ ). Further analysis demonstrated that 10 -items models have good indices of configural validity. In whole, the acquired results show that the short versions of the Social Dominance Orientation Scales correspond to the theoretical model, are reliable, valid and can be used in empirical research.
\end{abstract}

Keywords: social dominance theory, social dominance orientation.

\section{References}

Duckitt, J. (2001). A dual-process cognitive-motivational theory of ideology and prejudice. Advances in Experimental Social Psychology, 33, 41-114.

Etchezahar, E., Prado-Gascó, V., Jaume, L., \& Brussino, Y. S. (2014). Validación argentina de la escala de orientación a la dominancia social. Revista Latinoamericana de Psicología, 46, 35-43. doi:10.1016/S0120-0534(14)70004-4 (in Spanish)

Everett, J. A. C. (2013). The 12 Item Social and Economic Conservatism Scale (SECS). PLoS ONE, 8(12), e82131. doi:10.1371/journal.pone.0082131

Feather, N. T., \& McKee, I. R. (2012). Values, right-wing authoritarianism, social dominance orientation, and ambivalent attitudes toward women. Joumal of Applied Social Psychology, 42, 24792504.

Ho, A. K., Sidanius, J., Kteily, N., Sheehy-Skeffington, J., Pratto, F., Henkel, K. E., ... Stewart, A. L. (2015). The nature of social dominance orientation: Theorizing and measuring preferences for intergroup inequality using the new SDO7Scale. Joumal of Personality and Social Psychology, 109, 1003-1028. doi:10.1037/pspi0000033 
Ho, A. K., Sidanius, J., Pratto, F., Levin, S., Thomsen, L., Kteily, N., \& Sheehy-Skeffington, J. (2012). Social dominance orientation: Revisiting the structure and function of a variable predicting social and political attitudes. Personality and Social Psychology Bulletin, 38, 583-606.

Hodson, G., \& Dhont, K. (2015). The person-based nature of prejudice: Individual difference predictors of intergroup negativity. European Review of Social Psychology, 26, 1-42.

Jylhä, K. M., \& Akrami, N. (2015). Social dominance orientation and climate change denial: The role of dominance and system justification. Personality and Individual Differences, 86, 108-111.

Li, Z., Wang, L., Shi, J., \& Shi, W. (2006). Support for exclusionism as an independent dimension of social dominance orientation in mainland China. Asian Journal of Social Psychology, 9, 203-209. doi:10.1111/j.1467-839X.2006.00198.x

Livi, S. Leone, L., Falgares, G., \& Lombardo, F. (2014). Values, ideological attitudes and patriotism. Personality and Individual Differences, 64, 141-146.

Mifune, N., \& Yamagishi, T. (2008). The validity of Japanese version of social dominance orientation. Poster presented in the 72nd annual meeting of Japanese Psychological Association. 72nd Annual Convention of the Japanese Psychological Association, Hokkaido University, Sapporo, September 19, 2008.

Mosso, C., Briante, G., Aiello, A., \& Russo, S. (2013). The role of legitimizing ideologies as predictors of ambivalent sexism in young people: Evidence from Italy and the USA. Social Justice Research, 26, 1-17.

Perry, R., Sibley, C. G., \& Duckitt, J. (2013). Dangerous and competitive worldviews: A meta-analysis of their associations with social dominance orientation and right-wing authoritarianism. Journal of Research in Personality, 47, 116-127.

Pratto, F., Sidanius, J., \& Levin, S. (2006). Social dominance theory and the dynamics of intergroup relations: Taking stock and looking forward. European Review of Social Psychology, 17, 271-320. doi:10.1080/10463280601055772

Pratto, F., Sidanius, J., Stallworth, L. M., \& Malle, B. F. (1994). Social dominance orientation: A personality variable predicting social and political attitudes. Joumal of Personality and Social Psychology, 67, 741-763. doi:10.1037/0022-3514.67.4.741

Sibley, C. G., \& Duckitt, J. (2008). Personality and prejudice: A meta-analysis and theoretical review. Personality and Social Psychology Review, 11, 248-279.

Sibley, C. G., Robertson, A., \& Wilson, M. S. (2006). Social dominance orientation and right-wing authoritarianism: Additive and interactive effects. Political Psychology, 27, 755-768.

Sidanius, J., Pratto, F., van Laar, C., \& Levin, S. (2004). Social dominance theory: Its agenda and method. Political Psychology, 25, 845-880.

Olga A. Gulevich - professor, School of Psychology, Faculty of Social Sciences, National Research University Higher School of Economics, D.Sc.

Research area: psychology of intergroup relations, political psychology.

E-mail: gulevich@hse.ru

Elena R. Agadullina - associate professor, School of Psychology, Faculty of Social Sciences, National Research University Higher School of Economics, Ph.D.

Research area: social cognition, implicit theories.

E-mail: eagadullina@hse.ru

Oleg E. Khukhlaev - head, the department of Cross-Cultural Psychology and Multicultural Education, Moscow State University of Psychology \& Education, Ph.D.

Research area: cross-cultural psychology, intergroup relations, social-psychological training.

E-mail: huhlaevoe@mgppu.ru 